\title{
Can culture beat Covid-19? Evidence that exposure to facemasks with cultural symbols increases solidarity 00
}

\section{Rotem Perach () | Maliyana Limbu}

School of Psychology, University of Sussex, Brighton, UK

\section{Correspondence}

Rotem Perach, School of Psychology, University of Sussex, Falmer, Brighton BN1 9RH, UK. Email: r.perach@sussex.ac.uk

\section{Funding information}

RP was supported by a grant from the Early Career Research Fund, University of Sussex. ML was supported by the Doctoral School Junior Research Associate Scheme, University of Sussex.

\begin{abstract}
Facemasks have become integral to everyday life. We propose that exposure to facemasks with a solidarity-related cultural symbol can activate cultural values such as mutual trust and increase corresponding interpersonal perceptions, thereby enhancing collective resilience in the Covid-19 pandemic. In three (two of which preregistered) studies, we examined whether exposure to facemasks with a solidarityrelated cultural symbol predicts positive interpersonal perceptions, and whether this depends on death awareness. Across studies, exposure to facemasks with a cultural symbol (either pride flag or National Health Service) increased positive interpersonal perceptions, an index of solidarity, in people for whom this symbol represents a meaningful social identity. This was found whether participants were reminded of death, a neutral experience, or a negative experience. Importantly, in Study 3, exposure to facemasks with a solidarity-related cultural symbol (vs. surgical) led to greater increases in positive interpersonal perceptions when death awareness was high. Together, our findings suggest that wearing facemasks with a cultural symbol that relates to solidarity can be a vehicle for shaping people's personality impressions of others. Applied directions for the activation
\end{abstract}


of people's social identities via facemask selection to promote collective resilience in the Covid-19 pandemic are discussed.

\section{K E Y W O R D S}

covid-19, facemasks, social identity, solidarity, terror management theory

\section{BACKGROUND}

In the COVID-19 outbreak, facemasks have become integral to everyday life. Currently, wearing facemasks is recommended by the World Health Organization (2021) to suppress COVID-19 transmission (Howard et al., 2021; Wei et al., 2021). With the continuous mutation of the virus, protective measures such as facemask wearing are potentially here to stay (British Academy, 2021). Accordingly, research and theory concerning the psychological effects of facemask exposure (Biermann et al., 2021; Cartaud et al., 2020; Fitousi et al., 2021; Grundmann et al., 2021; Kastendieck et al., 2021; Klucarova, 2021; ParadaFernández et al., 2022; Rosa et al., 2020; Wu et al., 2021) and the associations attached to facemasks in general (Cheng et al., 2020; Huang et al., 2021; Ji, 2020; Timpka \& Nyce, 2021) and to specific types (e.g., surgical) of facemasks (Goh et al., 2020; Klucarova, 2021; Mokdad, 2021; Perach, 2020; Tateo, 2020) are emerging. In this article, we propose that exposure to facemasks with a cultural symbol that relates to solidarity can activate cultural values such as mutual trust and thereby increase interpersonal perceptions compatible with these values (Neville et al., 2021; Vail et al., 2012). In other words, in the COVID-19 pandemic, facemask selection can potentially promote solidarity by affecting people's malleable interpersonal perceptions (Cheng et al., 2020; Elcheroth \& Drury, 2020). In three studies, we test whether exposure to facemasks that make salient people's solidarity-related cultural values increases positive interpersonal perceptions, and whether these effects depend on people's awareness of their inevitable mortality.

In this article, we define people's positive interpersonal perceptions as positive personality impressions (Rosenberg et al., 1968) of other individuals; we operationalise these perceptions as individuals' perceived positive personality traits (e.g., trustworthy, reliable, Levine et al., 2018; Rosenberg et al., 1968); and view these perceptions as an index of solidarity in the face of COVID-19-a sense of fellow-feeling that unites people against the threat of the virus (Tomasini, 2021).

\section{Positive interpersonal perceptions, solidarity, and collective resilience}

The COVID-19 pandemic, declared in March 2020 (World Health Organization, 2020), presented significant challenges for individuals (e.g., Social Metrics Commission, 2020; Wu et al., 2021), intergroup relations (e.g., Jiang et al., 2021; Prosser et al., 2020), and societies (e.g. Abrams et al., 2021; Carothers \& Press, 2020; Mazey \& Richardson, 2020). In this context, the promotion of collective resilience is a major societal challenge (Elcheroth \& Drury, 2020).

Solidarity in the face of COVID-19 (Tomasini, 2021) is key to collective resilience (Elcheroth \& Drury, 2020; Jewett et al., 2021), and is tied to how people perceive others (Lalot et al., 2021; Pagliaro et al., 2021). For example, interpersonal perceptions of trust have been positively associated with intentions for discretionary behaviours such as buying supplies for people in need and donating to charities to help fight COVID-19 (Pagliaro et al., 2021) and social cohesion outcomes (Lalot et al., 2021). Forming a positive impression of a person (e.g., 'This person is trustworthy') can facilitate other positive personality impressions (e.g., reliable, Rosenberg et al., 1968), and the perception that this person is likely to be collaborative and helpful in times of need (Simpson, 2007). In this way, cues that help form 
our impressions of others, for example, indicators of shared group membership, can potentially lead to positive interpersonal perceptions and increased solidarity ('This person and I have shared beliefs and values, so this is a 'good' person that I can count on if needed') (e.g., Kramer \& Brewer, 1984; Levine et al., 2005).

People's faces are an important source for inferring people's personality (Todorov et al., 2009; Yan et al., 2015), even when partly covered by facemasks (Cartaud et al., 2020; Rosa et al., 2020; see Fitousi et al., 2021 for other interpersonal effects of facemasks). Below, we discuss the effects of facemasks on people's interpersonal perceptions and propose that these effects can depend on facemask type.

\section{Interpersonal perceptions of wearers of different facemasks}

During a pandemic, any type of facemask-wearing can potentially evoke a sense of social and cultural solidarity that transcends individual self-protection motives (Cheng et al., 2020). However, facemasks vary by type (Goh et al., 2020; Van Gorp, 2021), and different facemasks evoke different associations (Tateo, 2020). Quantitative research on the interpersonal effects of facemasks has thus far focused on surgical (or medical) facemasks (Cartaud et al., 2020; Fitousi et al., 2021; Grundmann et al., 2021; Kastendieck et al., 2021; Klucarova, 2021; Parada-Fernández et al., 2022; Rosa et al., 2020; Wu et al., 2021), a type of facemask traditionally used to stop bacteria transmission in medical settings (Goh et al., 2020). For example, in two articles, faces with a surgical facemask were rated as more trustworthy in comparison to faces with a neutral emotional expression, whether these faces were of virtual characters (Cartaud et al., 2020) or real-life individuals (Olivera-La Rosa et al., 2020). In another study, exposure to surgical facemasks increased competency perceptions and behavioural intentions (Klucarova, 2021). For current purposes, we define cultural facemasks as facemasks that depict a solidarity-related cultural symbol in the form of logo, icon, print, or letters. Next, we discuss two theoretical frameworks - the social identity approach, and terror management theory-for understanding the potential of cultural facemasks to activate solidarity-related cultural values and promote solidarity beyond other facemasks.

\section{Theoretical frameworks for understanding perceptions of cultural facemask-wearers}

\section{The social identity approach}

The social identity approach is an influential framework in social psychology that construes shared social identity as key to understanding people's interpersonal perceptions and behaviours (van Bavel \& Packer, 2021; Hornsey, 2008; Reicher et al., 2010). Building on social identity theory (Tajfel, 1978; Tajfel \& Turner, 1979) and social-categorisation theory (Turner et al., 1987, 1994), the social identity approach posits that social groups provide their members with social identity (i.e., how group members are defined) and prescriptions for normative behaviour as a group member. When a social identity is made salient, people use the corresponding group membership to define themselves and others, and act according to the group's norms and values (e.g., van Dick et al., 2009; James \& Greenberg, 1989; Levine et al., 2005). For example, in one study, Manchester United football club fans were more likely to intervene to help a (confederate) bystander in distress wearing a Manchester United (vs. rival team and plain) shirt (Levine et al., 2005). In other words, exposure to a shared social identity prime increased actual helping behaviour (Levine et al., 2005), consistent with group-relevant norms (Derbaix \& Decrop, 2011). In the context of the COVID-19 pandemic, the activation of a targeted social identity (e.g., national identity) can potentially shape the perceptions of people who subscribe to this identity ('As a Scottish national, I protect my fellow citizens') and related behaviours such as mask-wearing (Neville 
et al., 2021; Scottish Government, 2020). Thus, facemasks that activate a social identity that relates to solidarity (i.e., cultural facemasks) can be a social resource via triggering the provision of social support (Haslam et al., 2022).

\section{Terror Management Theory}

Terror Management Theory (TMT; Greenberg et al., 1986) is a psychological theory based on the works of Becker $(1971,1973)$ and Rank (1941). TMT proposes that the awareness of death is a fundamental motivator of human behaviour and focuses on the cultural mechanisms to manage this awareness. According to TMT, the awareness of death is at the root of an existential conflict unique to humans. On the one hand, like other organisms, humans are motivated to secure their continued existence. On the other hand, due to their developed cognitive capacities (e.g., symbolic thinking), humans are unique in understanding that their existence is inevitably finite. This conflict creates the potential for experiencing acute anxiety, or terror, which is managed by investing in two interrelated psychological structures. One structure is cultural worldviews: a set of socially constructed beliefs and values to which an individual prescribes that provide standards for understanding what is valuable and meaningful. TMT maintains that adherence to cultural worldviews holds the promise of either literal (i.e., promise of an after-life) or symbolic immortality in the face of death awareness. The second structure is self-esteem, which TMT posits is achieved by meeting standards of value prescribed by cultural worldviews (Solomon et al., 2004). Since its emergence, TMT has gained international support from hundreds of empirical studies (Burke et al., 2010; Pyszczynski et al., 2015). The replicability of TMT evidence is under ongoing discussion (Chatard et al., 2020; Klein et al., 2019).

One key TMT hypothesis is the Mortality Salience (MS) hypothesis (Rosenblatt et al., 1989), which posits that when people are reminded of their mortality, they display an increased reliance on cultural worldviews and self-esteem to buffer against mortality concerns. For example, when reminded of their mortality, people invest in culturally valued symbols by desiring a job in a company whose logo depicts a national symbol (Wirth-Petrik \& Guenther, 2012), showing increased reluctance to inappropriately use cultural objects (Greenberg et al., 1995), and negatively evaluating someone who criticises their country (Greenberg et al., 1990). Thus, evidence shows that the endorsement of cultural symbols is one way to manage the awareness of death and suggests that exposure to cultural symbols after death reminders can affect people's interpersonal perceptions.

MS and adherence to salient cultural values According to the Preliminary Heuristic Model of Positive Terror Management (Vail et al., 2012), when death awareness is high and cultural worldviews are made salient (e.g., by exposure to cultural symbols), these salient worldviews will guide people's psychological defences (Gailliot et al., 2008; Jonas et al., 2008). For example, in one field study, participants who walked through a cemetery (i.e., high death awareness) and were reminded of the value of helping showed increased helping behaviour to a stranger in comparison to those who did not pass by the cemetery (Gailliot et al., 2008). This finding was conceptually replicated using self-report measures of helping, and different mortality and cultural value priming methodologies (Gailliot et al., 2008). In other words, exposure to cultural values affected changes in value-relevant behaviours after death reminders. Additional insight into terror management processes when cultural values are salient comes from TMT-derived models that focus on the management of health threats, that is, the Terror Management Health Model (Arndt \& Goldenberg, 2017; Goldenberg \& Arndt, 2008), and its application for pandemics (Courtney et al., 2020). The Terror Management Health Model for pandemics (Courtney et al., 2020) construes mask-wearing as a behaviour motivated by both proximal defences (that manage conscious death thought) and distal defences (that manage non-conscious death thought) (Pyszczynski et al., 1999). Mask-wearing can be understood as a protective health-oriented behaviour that aims to reduce conscious perceived risk (proximal 
defence). At the same time, mask-wearing, especially cultural facemask-wearing that highlights cultural bases of value that are meaningful to the individual (Arndt \& Goldenberg, 2017), can be construed as a health-oriented behaviour that is informed by culture rather than health (distal defence). This view (Courtney et al., 2020) is thus in line with the notion that facemask wearing can potentially shape positive interpersonal perceptions ('I think positively of this cultural-facemask-wearer who is doing the "right thing") when death is salient. Overall, the above TMT-derived models are compatible with the idea that the activation of cultural values via exposure to a solidarity-related cultural symbol (i.e., on a cultural facemask) after death reminders can increase people's positive interpersonal perceptions.

Together, the above theoretical frameworks support the potential for cultural facemasks to increase positive interpersonal perceptions. Whereas the proposed underlying psychological processes are different, both frameworks share the notion that exposure to cultural symbols can steer people to endorse cultural-symbol-related perceptions. Namely, these effects are potentially driven by social identification with a salient ingroup identity (social identity approach), or by the management of death awareness through the validation of salient cultural worldviews (TMT). Building on these perspectives, in the current article, we examine whether exposure to cultural facemasks increases positive interpersonal perceptions, and whether these increases are affected by death reminders.

\section{The current studies}

Cultural facemasks have unique symbolic features that may activate solidarity-related cultural values. The activation of these cultural values has the potential for promoting collective resilience in the current COVID-19 pandemic, for example, via increasing adherence to public health messages (Elcheroth \& Drury, 2020). Grounded in the Preliminary Heuristic Model of Positive Terror Management (Vail et al., 2012), we hypothesise that exposure to cultural facemasks will affect people's interpersonal perceptions, particularly when death awareness is high (vs. low). Specifically, we predicted that exposure to facemasks with a solidarity-related cultural symbol will increase people's positive interpersonal perceptions, particularly when death is salient. We test this prediction in three studies using different cultural symbols, that is, pride flag (Study 1), and the UK National Health Service (Studies 2 and 3). Across studies, we targeted participants for whom the cultural symbol under study represents a meaningful social identity. For comparison, we included a no-mask control condition (Studies 1-3) and, to directly compare whether our effects differ by type of facemask, a surgical mask condition (Study 3). For presentation purposes, we report the studies in reversed chronological order.

\section{STUDY 1}

In Study 1 (preregistration: osf.io/8ahuy), we examined whether exposure to a cultural facemask increases positive interpersonal perceptions, and whether this depends on death awareness. In the cultural facemask condition, we exposed participants to individuals wearing a facemask with the pride flag. The pride flag is a symbol of societal and communal belongingness (Klapeer \& Laskar, 2018; Matsick et al., 2020), which represents a meaningful social identity to those who identify as gay or lesbian (Wolowic et al., 2017). In addition to the high MS condition, we included a neutral control condition, which enabled us to examine whether facemask exposure effects occur in the absence of death reminders. We predicted that exposure to wearers of a pride flag cultural facemask (vs. no mask) will increase positive interpersonal perceptions, particularly when death awareness is high (Vail et al., 2012). 


\section{Method}

\section{Participants and recruitment}

Across studies, we report all measures, manipulations, and exclusions. An a-priori power analysis (on $G^{*}$ Power 3.1.9.2) for ANOVA (main effects and interactions) showed that with an alpha $=.05$ and power $=0.80$, models used to test our hypothesis in a design with four groups require a sample size of 179 to detect our anticipated medium effect size, $f=.25$, comparable to the meta-analytic moderate effect of MS manipulations (Burke et al., 2010). The analytic sample comprised 178 (62\% women) users of crowdsourcing platform Prolific aged $18-52\left(M_{\text {age }}=23.75, S D_{\text {age }}=5.90\right)$ who were US residents, identified as gay or lesbian, and took part in exchange for $f^{1}$.1. Participants who did not meet the sexual orientation inclusion criterion were excluded from analysis $(n=22)$. The exclusion of six participants who identified the purpose of the study did not change the significance of the main findings. Data collection took place on 28 July 2021. At the time of the study, Centres for Disease Control and Prevention (CDC) guidance (2021b) dictated that only those who have not been fully vaccinated ( $\sim 50 \%$ of US population at the time of the study, Mathieu et al., 2021) should wear facemasks; and strong facemask mandates were not in place in some, but not all, states (Chiwaya, 2021). According to USA COVID-19 daily trends at this time (e.g., 492 new deaths), the time of the study was not a peak time (CDC, 2021a).

\section{Procedure and materials}

This online study had a 2 (MS: high, low) $\times 2$ (facemask: cultural mask, no mask) between-participants design. Participants completed nine filler items on the frequency of general activities (e.g., engaging in hobbies), an attention check, and were randomly allocated to either the high MS condition or a neutral control condition. In the high MS condition, participants completed two open-ended items: 'Briefly describe the emotions that the thought of your own death arouses in you' and 'Jot down, as specifically as you can, what you think will happen to you physically as you die and once you are physically dead' (Rosenblatt et al., 1989). Control participants completed two parallel items on reading books (Castano et al., 2002). Participants then completed the 20 -item Positive and Negative Affect Scales (PANAS; Watson et al., 1988). Items were rated on a scale ranging from 1 (very slightly or not at all) to 5 (extremely). A total mean score was computed for positive affect (10 items; Cronbach's $\alpha=.88$ ) and negative affect (10 items; Cronbach's $\alpha=.89)$. In line with the TMT paradigm, the PANAS served as a delay and distraction task because research has shown that MS effects occur when primed death thoughts are outside of consciousness and no longer attended to (Greenberg et al., 1994). Next, participants were randomly allocated to a facemask condition, in which they were exposed to four pictures of the same four individuals, who wore (1) no facemask or (2) a cultural facemask with the pride flag. The pictures were selected from the Chicago Face Database (Ma et al., 2015) with the inclusion criteria of mid-range ratings of attractiveness and honesty, set to rule out confounding baseline effects (see Olivera-La Rosa et al., 2020 for similar procedures). All pictures depicted neutral emotional expressions and were presented in equal size and resolution. For the masked conditions, we digitally added a facemask to each face. Participants were instructed that they could take as long as they needed to look at the pictures. After each picture, participants rated their interpersonal perceptions concerning the person in the picture (e.g., 'To me, this person seems trustworthy'; Cronbach's $\alpha$ per picture ranged .88-.92) on a scale ranging from 1 (strongly disagree) to 9 (strongly agree). This measure included adjectives that represent positive interpersonal perceptions (Levine et al., 2018; Rosenberg et al., 1968), namely, trustworthy, good-natured, dishonest (reversecoded), reliable, and sincere. A mean composite score was computed such that a higher score represented higher levels of positive interpersonal perceptions. Finally, participants were asked what in their opinion the purpose of the study was, provided background details including concerning 
COVID-19 (e.g., receiving a COVID-19 diagnosis), and were thanked and debriefed. The complete protocols of Studies 1-2 are available via the studies' preregistrations.

\section{Results}

\section{MS and affect}

ANOVA analyses showed no significant differences in positive affect and in negative affect between participants in the high (vs. low) MS condition, $p>.51, p=.06$, respectively. Thus, positive affect and negative affect did not meet our preregistered criteria for inclusion as covariates. ${ }^{1}$

\section{Main analyses}

\section{The effects of death reminders and facemask exposure on people's positive interpersonal perceptions}

We ran a two-way ANOVA with MS condition (dummy coded; 1 = high MS) and facemask condition (dummy coded; 1 = cultural pride flag facemask) as the independent variables. The dependent variable was positive interpersonal perceptions. Participants who were exposed to pride flag facemasks had significantly more positive interpersonal perceptions, $M=6.84, S D=1.24$, in comparison to those in the no facemask condition, $M=5.03, S D=.84, F(1,174)=129.95, p<.001, \eta_{p}^{2}=0.43$. There was no significant difference in positive interpersonal perceptions between participants who were reminded of death, $M=5.96, S D=1.26$, and those in the neutral control condition, $M=5.89$, $S D=1.53, p=.74$. The interaction between MS condition and facemask condition was not significant, $p=.56$ (Figure 1). Thus, cultural (pride) facemask exposure increased positive interpersonal perceptions across MS conditions.

\section{Discussion}

The findings of Study 1 showed that exposure to cultural pride flag facemasks increased positive interpersonal perceptions of mask-wearers, whether participants were reminded of death or a neutral topic. These findings provide initial support for our idea that exposure to cultural facemasks can increase solidarity by making salient solidarity-related cultural values. Nonetheless, Study 1 did not include a control group of a non-cultural facemask, and this limits our ability to infer that the findings are driven by exposure to the pride flag rather than reflect endorsement for mask wearing, behaviour at times mandated during the pandemic. Importantly, mixed state-level facemask mandates and CDC guidance at the time of the study suggest that the increased positive perceptions of cultural mask wearers do not reflect positive evaluations of people who comply with facemask mandates. In addition, the finding of Study 1 were obtained using a cultural symbol that represents a meaningful social identity for a minority of the population (Jones, 2021). Accordingly, in Study 2, we examine whether these effects conceptually replicate using a different cultural symbol that has a wider, national appeal.

\footnotetext{
${ }^{1}$ Considering evidence that MS induces changes in fear (Lambert et al., 2014), we explored this potential effect using two PANAS items that indexed fear (scared, afraid). These items were highly correlated across studies, $r_{\text {Stud } 1}=.79, r_{\text {Stud } 22}=.74, r_{\text {Stud } y 3}=.81$, all $p$ s $\leq .01$, and were averaged to create a fear index in each study. Across studies, MS increased the experience of fear: in Study 1, participants who were reminded of death had significantly higher fear scores, $M=2.06, S D=1.05$, in comparison to those in the neutral control condition, $M=1.69, S D=1.06, F(1$, $176)=5.21, p=.02$; in Study 2, participants who were reminded of death had significantly higher fear scores, $M=1.72, S D=0.83$, in comparison to those remined of pain, $M=1.45, S D=0.71, F(1,196)=5.72, p=.02$; in Study 3, participants who were reminded of death had significantly higher fear scores, $M=1.72, S D=0.83$, in comparison to those in the pain control condition, $M=1.85, S D=1.16, F(1$, $216)=8.92, p=.003$. To rule out the possibility that our effects are due to fear, we re-ran our analyses with fear as a covariate. Importantly, across studies, the inclusion of fear as a covariate did not change the significance of our main findings.
} 


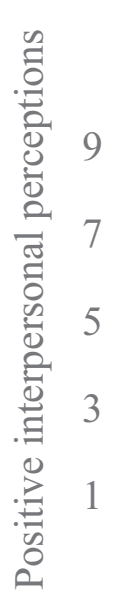

Study 1

- Cultural facemask

- No mask

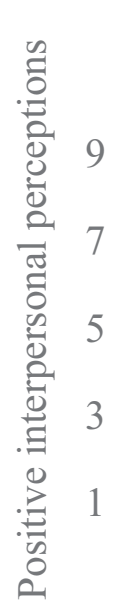

Study 2

High Low

Mortality salience

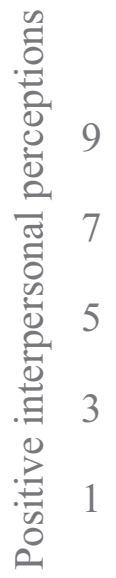

Study 3

Mortality salience

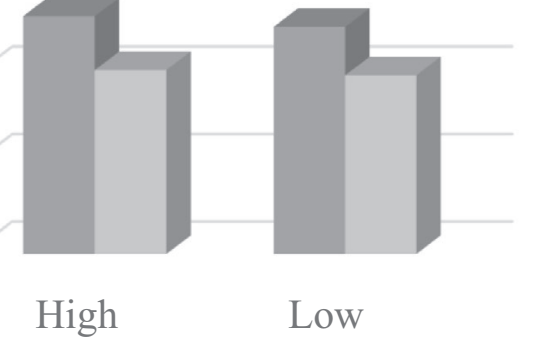

- Cultural facemask

- No mask

- Cultural facemask

- Surgical facemask

- No mask

High

Low

Mortality salience

F I G U R E 1 The interaction between MS and facemask exposure on positive interpersonal perceptions in Studies 1-3 


\section{STUDY 2}

In Study 2 (preregistration: osf.io/jd24 t), we tested our predictions using cultural facemasks with a symbol of solidarity and national identity in the UK, the National Health Service (NHS). The NHS stands for solidarity as seen, for example, in the weekly UK-wide 'clap for our carers' salutation to NHS workers in the early months of the COVID-19 outbreak (Tomasini, 2021). In the same vein, the NHS represents national pride as seen, for example, in the overwhelming support (84\%) for the belief that 'NHS is one of the best health systems in the world' in the English public during the second national lockdown (Duffy, 2020). In addition, in Study 2, we replaced the neutral control condition with a negative one (i.e., pain), standard in TMT literature. We hypothesised that participants in the NHS facemask (vs. no mask) condition would show higher levels of positive interpersonal perceptions, particularly when MS is high (Vail et al., 2012).

\section{Method}

\section{Participants and recruitment}

The power analysis was identical to Study 1. The analytic sample comprised 198 (64\% female) users of crowdsourcing platform Prolific aged $18-78\left(M_{\text {age }}=33.83, S D_{\text {age }}=12.64\right)$ who had a UK nationality, and took part in exchange for $f_{1} 1.3$. One participant who did not meet the UK nationality inclusion criterion was excluded from analysis. The exclusion of 23 participants who identified the purpose of the study did not change the significance of the main findings. Data collection took place on 9 June 2021 following the easing of COVID restrictions (e.g., removal of requirement to wear facemasks in classrooms) as part of Step 3 of the UK's roadmap out of lockdown (UK Government, 2021b). According to data on UK COVID-19 trends (e.g., 7,540 reported cases), this was not a peak time (UK Government, 2021a).

\section{Procedure and materials}

This online study had a 2 (MS: high, low) $\times 2$ (facemask: cultural mask, no mask) between-participants design. Participants completed three filler items on the frequency of general activities, an attention check, and were randomly allocated to a MS condition. The high MS condition was identical to Study 1. In the low MS condition, participants completed two parallel items on the experience of extreme physical pain (Juhl et al., 2010). Participants then completed the PANAS, which served as a delay and distraction task (Greenberg et al., 1994). Next, participants were randomly allocated to a facemask condition in which they were exposed to four pictures of the same four individuals, who either wore no facemask or a cultural NHS facemask (Figure 2), and rated their interpersonal perceptions concerning the person in the picture (as in Study 1). To increase stimulus variability (Judd et al., 2012), in this study, we used pictures of individuals different than those shown in Study 1 (Cronbach's $\alpha$ per picture ranged .84-.92), applying the same procedure. Finally, participants were asked what in their opinion the purpose of the study was, provided background details including concerning COVID-19 and were thanked and debriefed.

\section{Results}

\section{MS and affect}

ANOVA analyses showed no differences in positive affect or negative affect between participants in the high (vs. low) MS condition, $p=.62, p=.08$, respectively. Thus, positive affect and negative affect did not meet our preregistered criteria for inclusion as covariates. 

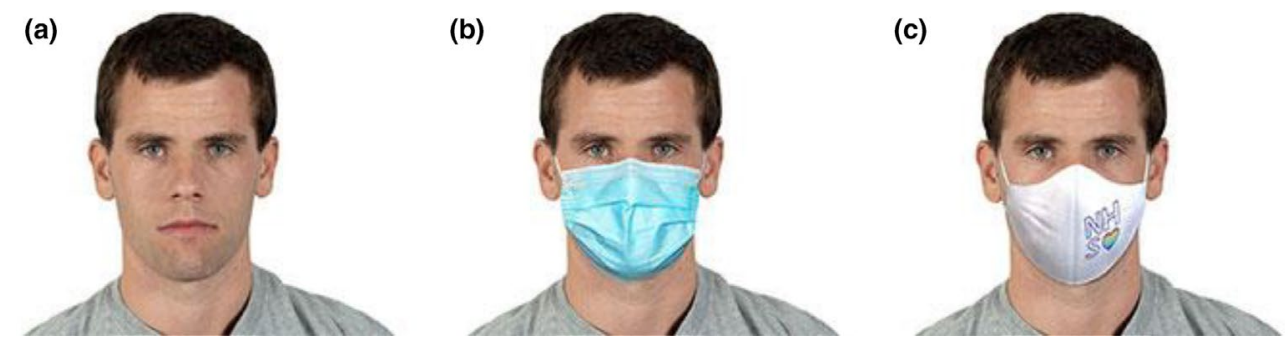

F I G U R E 2 Examples of pictures presented in the different facemask conditions: (a) no mask (Studies 2-3), (b) surgical mask (Study 3), and (c) cultural NHS mask (Studies 2-3)

\section{Main analyses}

The effects of death reminders and facemask exposure on people's positive interpersonal perceptions

We ran a two-way ANOVA with MS condition (dummy coded; 1 = high MS) and facemask condition (dummy coded; 1 = cultural NHS facemask) as the independent variables. The dependent variable was positive interpersonal perceptions. Participants who were exposed to NHS facemasks had significantly more positive interpersonal perceptions, $M=6.31, S D=1.27$, in comparison to those in the no facemask condition, $M=5.14, S D=.83, F(1,194)=58.60, p<.001, \eta_{p}^{2}=0.23$. There was no significant difference in positive interpersonal perceptions between participants who were reminded of death, $M=5.81, S D=1.21$, and those reminded of pain, $M=5.64, S D=1.23$, $p=.24$. The interaction between MS condition and facemask condition was not significant, $p=.69$ (Figure 1). Thus, cultural (NHS) facemask exposure increased positive interpersonal perceptions across MS conditions.

\section{Discussion}

The findings of Study 2 showed that cultural NHS facemask (vs. no mask) exposure increased positive interpersonal perceptions across MS conditions. Together, the findings of Studies 1-2 show provide novel evidence in support of our idea that exposure to cultural facemasks can increase solidarity. Specifically, the findings of Studies 1-2 converged in showing the effects of exposure to a facemask with a cultural symbol, whether pride flag or NHS, on positive interpersonal perceptions. These effects occurred whether participants were presented with a death, negative, or neutral reminder. Study 2 did not include a non-cultural facemask control group. However, data collection followed the easing of COVID restrictions in the UK. This suggests that, as in Study 1, the findings do not reflect endorsement of mask wearing guidance. A related issue is that the design of Studies 1-2 did not enable testing whether cultural facemasks are superior to other facemasks in eliciting positive interpersonal perceptions. In Study 3, we included surgical facemasks as an additional comparison condition.

\section{STUDY 3}

In Study 3, we examined whether exposure to different facemasks (i.e., cultural, surgical) increases positive interpersonal perceptions, and whether this depends on death awareness. We predicted that exposure to wearers of an NHS cultural facemask will increase positive interpersonal perceptions, particularly when death awareness is high (Vail et al., 2012). Importantly, Study 3 included both a no-mask control 
condition and a non-cultural facemask control condition, enabling us to directly compare whether our effects differ by type of facemask. ${ }^{2}$

\section{Method}

\section{Participants and recruitment}

An a-priori power analysis (on G*Power 3.1.9.2) for ANOVA (main effects and interactions) showed that with an alpha $=.05$ and power $=0.80$, models used to test our hypothesis in a design with six groups require a sample size of 211 to detect our anticipated medium effect size, $f=.25$ (Burke et al., 2010). The analytic sample comprised 218 (82\% female) UK university students aged $18-42\left(M_{\text {age }}=19.87\right.$, $S D_{\text {age }}=2.12$ ) who had a UK nationality, and took part in exchange for course credit. Participants who did not meet the UK nationality inclusion criterion were excluded from analysis $(n=19)$. The exclusion of two participants who identified the purpose of the study did not change the significance of the main findings. Data collection took place between $28^{\text {th }}$ of January and $28^{\text {th }}$ of April, 2021, following the start of the third national lockdown during which government advised people to 'stay home' and did not provide any explicit facemask guidance (Brown \& Kirk-Wade, 2021). The number of COVID-19 cases in the UK peaked in January, 2021 and majorly declined by April, 2021 (UK Government, 2021a).

\section{Procedure and materials}

This online study had a 2 (MS: high, low) $\times 3$ (facemask: no mask, surgical mask, cultural mask) betweenparticipants design. Participants completed three filler items on the frequency of general activities, an attention check, and were randomly allocated to a MS condition (the experimental and control condition were identical to Study 2). Participants then completed the PANAS (Watson et al., 1988), which served to create a delay and distraction (Greenberg et al., 1994). Next, participants were randomly allocated to a facemask condition in which they were exposed to and rated interpersonal perceptions of four individuals who wore (1) no facemask, (2) a surgical facemask, or (3) a cultural NHS facemask (Figure 2). In this study, we used pictures of the individuals shown in Study 2 and followed the procedure described in Study 1. Finally, participants were asked what in their opinion the purpose of the study was, provided background details including concerning COVID-19, and were thanked and debriefed.

\section{Results}

\section{MS and affect}

ANOVA analyses showed that participants in the high MS condition had increased positive affect, $M=23.06, S D=7.71$, in comparison to those in the low MS condition, $M=21.13, S D=6.92, F$

\footnotetext{
${ }^{2}$ To explore the possibility of individual differences in the management of death awareness after exposure to facemasks (Kelley et al., 2015; Olivera-La Rosa et al., 2020), Study 3 included a measure of disgust sensitivity (Tybur et al., 2009). In addition, because the NHS is a symbol of national identity (Stubley, 2020), and because death reminders can increase people's optimism when their national identity is salient (Dechesne et al., 2000), we further examined the possibility that exposure to cultural facemasks after death reminders will increase people's optimism. These supplementary analyses showed null effects and therefore measures and results are briefly reported herein: Participants' first assessment was the 7-item pathogen disgust sensitivity scale, a subscale of the Three Domain Disgust Scale (Tybur et al., 2009). Following the interpersonal perceptions measure, participants completed a 3-item measure of optimism based on the Revised Life Orientation Test (Scheier et al., 1994), modified to evaluate state optimism (Kluemper et al., 2009). An ANOVA analysis testing the effects of MS condition and facemask condition on optimism showed no significant main or interaction effects, all $p$ s $>$. 66. In linear regressions with 1. positive social perceptions and 2. optimism as the dependent variable, there were no significant 3-way interactions between pathogen disgust sensitivity, MS condition, and facemask condition on positive interpersonal perceptions, and on optimism, all ps >.10.
} 
$(1,216)=3.79, p=.053$. Also, participants in the high MS condition had increased negative affect, $M=18.44, S D=8.41$, in comparison to those in the low MS condition, $M=16.45, S D=6.91, \mathrm{~F}$ (1, 216) $=3.65, p=.057$. To rule out the possibility that our effects are due to affect, we re-ran subsequent analyses with positive affect and negative affect as covariates. This inclusion did not change the significance of the main findings.

\section{Main analyses}

We ran a two-way ANOVA with MS condition (dummy coded; 1 = high MS) and facemask condition (dummy coded; 1 = cultural NHS facemask) as the independent variables. The dependent variable was positive interpersonal perceptions.

\section{The effects of death reminders and facemask exposure on positive interpersonal perceptions}

In our analysis of the effects on positive interpersonal perceptions, the only significant main effect was for facemask condition, $F(2,212)=17.54, p<.001, \eta_{p}^{2}=0.14$. As hypothesised, there was a significant interaction between MS condition and facemask condition, $F(2,212)=3.69, p=.03, \eta_{p}^{2}=0.03$ (Figure 1). Means (SDs), sample size per cell, and significant differences in positive interpersonal perceptions are presented in Table 1.

Simple effects analyses showed that within the cultural facemask condition, participants who were reminded of their mortality had significantly more positive interpersonal perceptions in comparison to those in the low MS condition, $p=.01$. Within the no mask and surgical facemask conditions, there were no significant differences among participants in the high (vs. low) MS condition, $p=.29, p=.98$, respectively. Thus, in line with our predictions, facemask exposure increased positive interpersonal perceptions among participants who were reminded (vs. not reminded) of their mortality, but only in the cultural facemask condition (Table 1). Looked at differently, within the high MS condition, participants who viewed the cultural facemask had significantly more positive interpersonal perceptions in comparison to those in the surgical facemask, $p<.001$, and no facemask, $p=.04$, conditions. Also, participants in the surgical facemask condition had significantly more positive interpersonal perceptions in comparison to those in the no mask condition, $p<.001$. Within the low MS condition, participants in the no mask condition had significantly less positive interpersonal perceptions in comparison to those in the cultural facemask, $p=03$, and surgical facemask, $p=.01$, conditions (Table 1). There were no differences between participants in the cultural facemask and surgical facemask conditions, $p=.55$. Thus, whereas exposure to cultural and surgical facemasks (vs. no mask) led to comparable increases in positive interpersonal perceptions when MS was low, cultural facemasks led to greater increases when MS was high.

TA B L E 1 Means (SDs), sample size per cell, and significant differences in positive interpersonal perceptions

\begin{tabular}{|c|c|c|c|}
\hline & \multicolumn{3}{|l|}{ Facemask } \\
\hline & Cultural $^{\mathrm{a}, \mathrm{b}, \mathrm{c}}$ & Surgical $^{\mathrm{c}}$ & No mask \\
\hline & $M(S D), n$ & & \\
\hline \multicolumn{4}{|l|}{ MS } \\
\hline High & $6.33(0.95), 34$ & $5.88(1.06), 39$ & $5.06(0.62), 34$ \\
\hline Low & $5.74(0.94), 38$ & 5.88 (1.12), 33 & $5.29(0.82), 40$ \\
\hline
\end{tabular}

asignificant difference between high and low MS conditions.

${ }^{\mathrm{b}}$ Significant difference in comparison to no mask and surgical facemask conditions in the high MS condition.

${ }^{\mathrm{c}}$ Significant difference in comparison to no mask condition in the low MS condition. 


\section{Discussion}

In Study 3, we tested whether exposure to wearers of an NHS cultural facemask (vs. surgical and no mask) increases positive interpersonal perceptions, an index of solidarity, particularly when death awareness is high. In line with the evidence obtained in Studies 1-2, the findings of Study 3 show that exposure to cultural facemasks (vs. no mask) increased positive interpersonal perceptions whether death awareness was high or low. Also, the findings of Study 3 show that exposure to cultural facemasks increased positive interpersonal perceptions in comparison to surgical facemasks, but only when death awareness was high. Overall, the findings support our TMT-derived idea that the cultural, but not surgical, facemasks carry symbolic features that can increase solidarity when people are reminded of death (Vail et al., 2012).

\section{GENERAL DISCUSSION}

In three studies, exposure to facemasks with a cultural symbol increased positive interpersonal perceptions. This was found when exposing participants to individuals wearing pride flag (Study 1) and NHS (Studies 2-3) cultural facemasks, and whether participants were reminded of death, a neutral experience, or a negative experience. Importantly, whereas exposure to cultural and surgical facemask led to comparable increases in positive interpersonal perceptions when death awareness was low, exposure to cultural facemasks led to greater increases when death awareness was high (Study 3). The current findings thus go beyond previous evidence on the effects of surgical facemask exposure on interpersonal perceptions (Cartaud et al., 2020; Olivera-La Rosa et al., 2020) and demonstrate that the psychological effects of exposure to facemasks can differ by type of mask. Together, our findings show that wearing cultural facemasks increases positive interpersonal perceptions, an index of solidarity, in some cases more so than surgical facemasks.

Across studies, exposure to facemasks with a cultural symbol increased positive interpersonal perceptions in people for whom this symbol represents a meaningful social identity. This was found using different sets of pictures (Judd et al., 2012), selected to rule out the possibility of baseline differences in trustworthiness based on norming data (Ma et al., 2015). From a social identity approach perspective (Neville et al., 2021), it is possible that the activation of a meaningful solidarity-related social identity increased people's positive interpersonal perceptions of others. Future research could include measures of social identification (e.g., Postmes et al., 2013) to directly examine whether identification with the targeted ingroup mediates the relationship between cultural facemask exposure and positive interpersonal perceptions.

As hypothesised, exposure to cultural (vs. surgical) facemasks led to greater increases in positive interpersonal perceptions when death awareness was high (Study 3). These findings are consistent with the TMT perspective (Vail et al., 2012) that people can manage the awareness death by adhering to salient cultural worldviews (Gailliot et al., 2008; Jonas et al., 2008). Also, it is possible that cultural, but not surgical, facemasks reminded people of enduring human creativity that embodies key cultural values (e.g., beauty) in the face of death, thereby affirming people's symbolic, long-lasting existence as cultural members (Perach, 2020; Perach \& Wisman, 2019). In other words, the findings of Study 3 suggest that exposure to cultural facemasks can activate terror management processes that relate to humans' unique capacity for culture (Greenberg et al., 1986), with the potential for enhancing collective resilience. Nonetheless, in Studies 1-2, we found no support for our TMT-derived hypothesis, such that it is too early to draw strong conclusions concerning the association between death reminders, cultural facemask exposure, and positive interpersonal perceptions. One possibility relating to the findings of Studies 2-3 is that public support for the NHS has shifted over the course of the pandemic. However, there are multiple indications of public NHS support during 2020 (Duffy, 2020; itvnews, 2020; Tomasini, 2021) and the shared meanings attached to cultural symbols do not readily fluctuate (Danesi \& Perron, 1999), suggesting that differences in the effects of death reminders in Studies 2 and 
3 are not due to changes in public perceptions of the NHS. Also, peak COVID-19 times can involve chronic death salience (Pyszczynski et al., 2020), which can potentially hinder the manifestation of the effects of death reminders. However, Studies 1-2 data collection took place during non-peak times, suggesting that this is an unlikely account for our findings. Future research could examine whether the interpersonal effects of exposure to cultural facemask after death reminders depends on type of death reminders (i.e., COVID-19-related, Courtney et al., 2021).

\section{Practical implications}

Our findings that exposure to cultural facemasks increased positive interpersonal perceptions suggest that the facemasks that people choose to wear can have important social implications (Elcheroth \& Drury, 2020). For example, the delivery of public health messages using figures that wear a cultural facemask could potentially increase facemask use among targeted social groups (Elcheroth \& Drury, 2020). In addition, the use of cultural facemasks can potentially serve to inspire solidarity and positive intergroup relations in settings of potential social conflict such as protests (Nassauer, 2019) and sport events (Newson, 2017), for example, via the activation of a superordinate (e.g., national) social identity (Levine et al., 2005; Neville et al., 2021). Finally, our findings suggest that the use of cultural facemasks can increase positive interpersonal perceptions towards staff in hospitals and health clinics (where death awareness is arguably high), thereby potentially serving to prevent abuse towards medical staff in the COVID-19 pandemic (Mahase, 2021). Future research incorporating measures of people's interpersonal perceptions and behaviours is needed to examine whether the current findings extend to these suggested applications.

\section{Limitations and future directions}

The three studies reported in this article, two of which preregistered, provide novel evidence that different cultural facemasks increase positive interpersonal perceptions, an index of solidarity. The current examination of different theoretical explanations promotes integrative social psychology science (Mather, 2007). For example, future research could examine whether the effects of cultural facemasks exposure after death reminders are more pronounced among those who more strongly subscribe to the cultural worldviews made salient - a notion compatible with both social identity (Lalonde, 2002) and terror management (Schimel et al., 2006) processes. Nonetheless, this research is not without limitations. Our TMT-derived hypothesis was supported in one of the three studies. In view of current discussion concerning the replicability of TMT effects (Chatard et al., 2020; Klein et al., 2019), future replications of the finding that exposure to cultural (vs. surgical) facemasks increases positive interpersonal perceptions when death is salient are needed. A related point is that none of our studies included a control condition of facemask with a non-solidarity-related cultural symbol; the inclusion of such a control mask, for example, using symbols of hate (Anti Defamation League, 2021) in studies of populations who do not subscribe to the worldviews that these symbols represent, is a direction for future research. Also, future studies could examine whether solidarity gains due to the activation of social identities via cultural facemask exposure are more pronounced among ingroup (vs. outgroup) members (Levine et al., 2005). In addition, mask-wearing can signal mask-wearers' individual beliefs (e.g., belief in science, Ike et al., 2020), thereby affecting people's interpersonal perceptions. Of note, in Studies 2-3, we used a prime of national identity, a major contributor to the formation of individual beliefs (Akaliyski et al., 2021), and across studies, strong facemask mandates were not in place at the time of data collection (in Study 1 this refers to some, but not all, state-level mandates, Chiwaya, 2021), thereby reducing potential confounding effects relating to these mandates. 


\section{CONCLUSIONS}

This article provides empirical support to the idea that cultural facemasks are not simply a fashion accessory, but rather a vehicle for shaping people's personality impressions of others (Perach, 2020). In three studies, we have used different methodologies in a variety of populations, and have shown that people's faces are an important source for inferring character (Todorov et al., 2009) when wearing facemasks with solidarity-related cultural symbols. Importantly, cultural facemasks increased positive personality impressions of others, in some cases beyond surgical facemasks. Thus, the current findings raise novel applied directions for the activation of people's social identities via facemask selection to promote collective resilience in the COVID-19 pandemic and beyond.

\section{ACKNOWLEDGEMENTS}

The authors thank John Drury and Eleanor Miles for their support and helpful insights. We thank Doron Hirsch and Kristina Petrova for helping with the graphic design of the images used in this research.

\section{AUTHOR CONTRIBUTION}

Rotem Perach: Conceptualization;Datacuration; Formalanalysis; Fundingacquisition; Investigation; Methodology; Project administration; Resources; Supervision; Validation; Visualization; Writing original draft; Writing - review \& editing. Maliyana Limbu: Conceptualization; Formal analysis; Funding acquisition; Investigation; Methodology; Project administration; Resources; Writing - review \& editing.

\section{OPEN RESEARCH BADGES}

\section{0}

This article has been awarded Open Data, Open Materials, Preregistered Badges. The materials of Study 1 and Study 2 are publicly accessible via the Open Science Framework at https://osf.io/8ahuy/ (Study 1), and https://osf.io/jd24t/ (Study 2).

\section{DATA AVAILABILITY STATEMENT}

The data that support the findings of this research are openly available in figshare at https://figshare. com/projects/Can_culture_beat_Covid-19_Data_and_syntax/127592.

\section{ORCID}

Rotem Perach (i) https://orcid.org/0000-0002-8647-4367

\section{REFERENCE}

Abrams, D., Lalot, F., \& Hogg, M. A. (2021). Intergroup and intragroup dimensions of COVID-19: A social identity perspective on social fragmentation and unity. Group Processes \& Intergroup Relations, 24(2), 201-209. https://doi.org/10.1177/13684 30220983440

British Academy (2021). Shaping the Covid decade: Understanding the long-term societal impacts of COVID-19. Retrieved from https:/www.thebritishacademy.ac.uk/publications/shaping-the-covid-decade-addressing-the-long-term-societalimpacts-of-covid-19/

Akaliyski, P., Welzel, C., Bond, M. H., \& Minkov, M. (2021). On “nationology": The gravitational field of national culture. Journal of Cross-Cultural Psychology, 52(8-9), 771-793. https://doi.org/10.1177/00220221211044780

Anti Defamation League (2021). Hate on display ${ }^{\mathrm{TM}}$ hate symbols database. Retrieved from https://www.adl.org/hate-symbo ls?page $=1$

Arndt, J., \& Goldenberg, J. L. (2017). Where health and death intersect: Insights from a Terror Management Health Model. Current Directions in Psychological Science, 26(2), 126-131. https://doi.org/10.1177/0963721416689563

Becker, E. (1971). The birth and death of meaning. Free Press.

Becker, E. (1973). The denial of death. Free Press. 
Biermann, M., Schulze, A., Unterseher, F., Atanasova, K., Watermann, P., Krause-Utz, A., Stahlberg, D., Bohus, M., \& Lis, S. (2021). Trustworthiness appraisals of faces wearing a surgical mask during the Covid-19 pandemic in Germany: An experimental study. PLoS One, 16(5), e0251393. https://doi.org/10.1371/journal.pone.0251393

Brown, J., \& Kirk-Wade, E. (2021). Coronavirus: A history of English lockdown laws. Retrieved from https://researchbriefings.files. parliament.uk/documents/CBP-9068/CBP-9068.pdf

Burke, B. L., Martens, A., \& Faucher, E. H. (2010). Two decades of terror management theory: A meta-analysis of mortality salience research. Personality and Social Psychology Review, 14(2), 155-195. https://doi.org/10.1177/1088868309352321

Carothers, T., \& Press, B. (2020). The global rise of anti-lockdown protests - and what to do about it. World Politics Review. Retrieved from https://www.worldpoliticsreview.com/articles/29137/amid-the-covid-19-pandemic-protest-movements-challengelockdowns-worldwide

Cartaud, A., Quesque, F., \& Coello, Y. (2020). Wearing a face mask against Covid-19 results in a reduction of social distancing. PLoS One, 15(12), e0243023. https://doi.org/10.1371/journal.pone.0243023

Castano, E., Yzerbyt, V., Paladino, M.-P., \& Sacchi, S. (2002). I belong, therefore, I exist: Ingroup identification, ingroup entitativity, and ingroup bias. Personality and Social Psychology Bulletin, 28(2), 135-143. https://doi.org/10.1177/0146167202282001

Centers for Disease Control and Prevention (2021a). Trends in number of COVID-19 cases and deaths in the US reported to CDC, by State/territory. Retrieved from https://covid.cdc.gov/covid-data-tracker/\#trends_dailydeaths_7daycasesper100k\%7Cnew_death\%7Cseven_day_cum_new_cases_per_100k

Centers for Disease Control and Prevention (2021b). Your guide to masks. Retrieved from https://www.cdc.gov/coronaviru s/2019-ncov/prevent-getting-sick/about-face-coverings.html

Chatard, A., Hirschberger, G., \& Pyszczynski, T. (2020). A word of caution about Many Labs 4: If you fail to follow your preregistered plan, you may fail to find a real effect. PsyArXiv, https://doi.org/10.31234/osf.io/ejubn

Cheng, K. K., Lam, T. H., \& Leung, C. C. (2020). Wearing face masks in the community during the COVID-19 pandemic: Altruism and solidarity. The Lancet, https://doi.org/10.1016/S0140-6736(20)30918-1

Chiwaya, N. (2021). Mask tracker: Does your state still require face masks?. NBC News. https://www.nbcnews.com/news/us-news/ map-mask-mandate-tracker-2021-n1269023

Courtney, E. P., Felig, R. N., \& Goldenberg, J. L. (2021). Together we can slow the spread of COVID-19: The interactive effects of priming collectivism and mortality salience on virus-related health behaviour intentions. British Journal of Social Psychology, 61(1), 410-431. https://doi.org/10.1111/bjso.12487

Courtney, E. P., Goldenberg, J. L., \& Boyd, P. (2020). The contagion of mortality: A terror management health model for pandemics. British Journal of Social Psychology, 59(3), 607-617. https://doi.org/10.1016/S0140-6736(20)30918-1

Danesi, M., \& Perron, P. (1999). Analyzing cultures: An introduction and handbook. Indiana University Press.

Dechesne, M., Greenberg, J., Arndt, J., \& Schimel, J. (2000). Terror management and the vicissitudes of sports fan affiliation: The effects of mortality salience on optimism and fan identification. European Journal of Social Psychology, 30(6), 813-835.

Derbaix, C., \& Decrop, A. (2011). Colours and scarves: An ethnographic account of football fans and their paraphernalia. Leisure Studies, 30(3), 271-291. https://doi.org/10.1080/02614367.2010.527356

Duffy, B. (2020). The NHS and public health: Perceptions vs reality. The Health Foundation, REAL Centre. Retrieved from https:// www.kcl.ac.uk/policy-institute/assets/nhs-and-public-health-perceptions-vs-reality.pdf

Elcheroth, G., \& Drury, J. (2020). Collective resilience in times of crisis: Lessons from the literature for socially effective responses to the pandemic. British Journal of Social Psychology, 59(3), 703-713. https://doi.org/10.1111/bjso.12403

Fitousi, D., Rotschild, N., Pnini, C., \& Azizi, O. (2021). Understanding the impact of face masks on the processing of facial identity, emotion, age, and gender. Frontiers in Psychology, 12, 743793. https://doi.org/10.3389/fpsyg.2021.743793

Gailliot, M. T., Stillman, T. F., Schmeichel, B. J., Maner, J. K., \& Plant, E. A. (2008). Mortality salience increases adherence to salient norms and values. Personality and Social Psychology Bulletin, 34(7), 993-1003. https://doi.org/10.1177/01461 67208316791

Goh, Y., Tan, B. Y., Bhartendu, C., Ong, J. J., \& Sharma, V. K. (2020). The face mask: How a real protection becomes a psychological symbol during Covid-19? Brain, Behavior, and Immunity, 88, 1-5. https://doi.org/10.1016/j.bbi.2020.05.060

Goldenberg, J. L., \& Arndt, J. (2008). The implications of death for health: A terror management health model for behavioral health promotion. Psychological Review, 115(4), 1032-1053. https://doi.org/10.1037/a0013326

Greenberg, J., Porteus, J., Simon, L., Pyszczynski, T., \& Solomon, S. (1995). Evidence of a terror management function of cultural icons: The effects of mortality salience on the inappropriate use of cherished cultural symbols. Personality and Social Psychology Bulletin, 21(11), 1221-1228. https://doi.org/10.1177/01461672952111010

Greenberg, J., Pyszczynski, T., \& Solomon, S. (1986). The causes and consequences of a need for self-esteem: A terror management theory. In R. F. Baumeister (Ed.), Public self and private self (pp. 189-212). Springer.

Greenberg, J., Pyszczynski, T., Solomon, S., Rosenblatt, A., Veeder, M., Kirkland, S., \& Lyon, D. (1990). Evidence for terror management theory II: The effects of mortality salience on reactions to those who threaten or bolster the cultural worldview. Journal of Personality and Social Psychology, 58(2), 308-318. https://doi.org/10.1037/0022-3514.58.2.308

Greenberg, J., Pyszczynski, T., Solomon, S., Simon, L., \& Breus, M. (1994). Role of consciousness and accessibility of deathrelated thoughts in mortality salience effects. Journal of Personality and Social Psychology, 67(4), 627-637. https://doi.org/10.1 037/0022-3514.67.4.627 
Grundmann, F., Epstude, K., \& Scheibe, S. (2021). Face masks reduce emotion-recognition accuracy and perceived closeness. PLoS One, 16(4), e0249792. https://doi.org/10.1371/journal.pone.0249792

Haslam, S. A., Haslam, C., Cruwys, T., Jetten, J., Bentley, S. V., Fong, P., \& Steffens, N. K. (2022). Social identity makes groupbased social connection possible: Implications for loneliness and mental health. Current Opinion in Psychology, 43, 161-165. https://doi.org/10.1016/j.copsyc.2021.07.013

Hornsey, M. J. (2008). Social identity theory and self-categorization theory: A historical review. Social and Personality Psychology Compass, 2(1), 204-222. https://doi.org/10.1111/j.1751-9004.2007.00066.x

Howard, J., Huang, A., Li, Z., Tufekci, Z., Zdimal, V., van der Westhuizen, H.-M., von Delft, A., Price, A., Fridman, L., Tang, L.-H., Tang, V., Watson, G. L., Bax, C. E., Shaikh, R., Questier, F., Hernandez, D., Chu, L. F., Ramirez, C. M., \& Rimoin, A. W. (2021). An evidence review of face masks against COVID-19. Proceedings of the National Academy of Sciences, 118(4), e2014564118. https://doi.org/10.1073/pnas.2014564118

Huang, R., Huang, R., \& Huang, E. (2021). Social influences on Americans' mask-wearing behavior during COVID-19. International Journal of Humanities and Social Sciences, 15(5), 536-544.

Ike, J. D., Bayerle, H., Logan, R. A., \& Parker, R. M. (2020). Face masks: Their history and the values they communicate. Journal of Health Communication, 25(12), 990-995. https://doi.org/10.1080/10810730.2020.1867257

itvnews (2020). Nationwide clap and Spitfire flypast mark. 72nd anniversary of NHS. Retrieved from https://www.itv.com/news/202007-05/leaders-pay-tribute-to-nhs-ahead-of-nationwide-clap-to-mark-72nd-anniversary

James, K., \& Greenberg, J. (1989). In-group salience, intergroup comparison, and individual performance and self-esteem. Personality and Social Psychology Bulletin, 15(4), 604-616. https://doi.org/10.1177/0146167289154013

Jewett, R. L., Mah, S. M., Howell, N., \& Larsen, M. M. (2021). Social cohesion and community resilience during COVID-19 and pandemics: A rapid scoping review to inform the United Nations research roadmap for COVID-19 recovery. International Journal of Health Services, 51(3), 325-336. https://doi.org/10.1177/0020731421997092

Ji, P. (2020). Masking morality in the making: how China's anti-epidemic promotional videos present facemask as a technomoral mediator. Social Semiotics, 1-8. https://doi.org/10.1080/10350330.2020.1810462

Jiang, X., Su, M.-H., Hwang, J., Lian, R., Brauer, M., Kim, S., \& Shah, D. (2021). Polarization over Vaccination: Ideological differences in twitter expression about COVID-19 vaccine favorability and specific hesitancy concerns. Social Media + Society, 7(3), 205630512110484.

Jonas, E., Martens, A., Niesta Kayser, D., Fritsche, I., Sullivan, D., \& Greenberg, J. (2008). Focus theory of normative conduct and terror-management theory: The interactive impact of mortality salience and norm salience on social judgment (pp. 1239-1251). American Psychological Association.

Jones, J. M. (2021). LGBT identification rises to $5.6 \%$ in latest U.S. estimate. Gallup. Retrieved from https://news.gallup.com/ poll/329708/lgbt-identification-rises-latest-estimate.aspx

Judd, C. M., Westfall, J., \& Kenny, D. A. (2012). Treating stimuli as a random factor in social psychology: A new and comprehensive solution to a pervasive but largely ignored problem (pp. 54-69). American Psychological Association.

Juhl, J., Routledge, C., Arndt, J., Sedikides, C., \& Wildschut, T. (2010). Fighting the future with the past: Nostalgia buffers existential threat. Journal of Research in Personality, 44(3), 309-314. https://doi.org/10.1016/j.jrp.2010.02.006

Kastendieck, T., Zillmer, S., \& Hess, U. (2021). (Un)mask yourself! Effects of face masks on facial mimicry and emotion perception during the COVID-19 pandemic. Cognition and Emotion, 1-11, https://doi.org/10.1080/02699931.2021.1950639

Kelley, N. J., Crowell, A. L., Tang, D., Harmon-Jones, E., \& Schmeichel, B. J. (2015). Disgust sensitivity predicts defensive responding to mortality salience. Emotion, 15(5), 590-602. https://doi.org/10.1037/a0038915

Klapeer, C. M., \& Laskar, P. (2018). Transnational ways of belonging and queer ways of being. Exploring transnationalism through the trajectories of the rainbow flag. Identities, 25(5), 524-541. https://doi.org/10.1080/1070289X.2018.1507958

Klein, R. A., Cook, C. L., Ebersole, C. R., Vitiello, C., Nosek, B. A., Chartier, C. R., Christopherson, C. D., Clay, S., Collisson, B., Crawford, J., Cromar, R., Vidamuerte, D., Gardiner, G., Gosnell, C., Grahe, J., Hall, C., Joy-Gaba, J., Legg, A. M., Levitan, C., ... Crawford, J. (2019). Many Labs 4: Failure to replicate mortality salience effect with and without original author involvement. Psy ArXiv. https://doi.org/10.31234/osf.io/vef2c

Klucarova, S. (2021). Do masks matter? Consumer perceptions of social media influencers who wear face masks amid the COVID-19 pandemic. Applied Psychology, 1-15. https://doi.org/10.1111/apps.12345

Kluemper, D. H., Little, L. M., \& DeGroot, T. (2009). State or trait: Effects of state optimism on job-related outcomes. Journal of Organizational Behavior, 30(2), 209-231. https://doi.org/10.1002/job.591

Kramer, R. M., \& Brewer, M. B. (1984). Effects of group identity on resource use in a simulated commons dilemma. Journal of Personality and Social Psychology, 46(5), 1044-1057. https://doi.org/10.1037/0022-3514.46.5.1044

Lalonde, R. N. (2002). Testing the social identity-intergroup differentiation hypothesis: 'We're not American eh!'. British Journal of Social Psychology, 41(4), 611-630. https://doi.org/10.1348/014466602321149902

Lalot, F., Abrams, D., Broadwood, J., Davies Hayon, K., \& Platts-Dunn, I. (2021). The social cohesion investment: Communities that invested in integration programmes are showing greater social cohesion in the midst of the COVID-19 pandemic. Journal of Community \& Applied Social Psychology, 1-11. https://doi.org/10.1002/casp.2522

Lambert, A. J., Eadeh, F. R., Peak, S. A., Scherer, L. D., Schott, J. P., \& Slochower, J. M. (2014). Toward a greater understanding of the emotional dynamics of the mortality salience manipulation: Revisiting the "affect-free" claim of terror management research. Journal of Personality and Social Psychology, 106(5), 655-678. https://doi.org/10.1037/a0036353 
Levine, E. E., Bitterly, T. B., Cohen, T. R., \& Schweitzer, M. E. (2018). Who is trustworthy? Predicting trustworthy intentions and behavior. Journal of Personality and Social Psychology, 115(3), 468-494. https://doi.org/10.1037/pspi0000136

Levine, M., Prosser, A., Evans, D., \& Reicher, S. (2005). Identity and emergency intervention: How social group membership and inclusiveness of group boundaries shape helping behavior. Personality and Social Psychology Bulletin, 31(4), $443-453$. https://doi.org/10.1177/0146167204271651

Ma, D. S., Correll, J., \& Wittenbrink, B. (2015). The Chicago face database: A free stimulus set of faces and norming data. Behavior Research Methods, 47(4), 1122-1135. https://doi.org/10.3758/s13428-014-0532-5

Mahase, E. (2021). Doctors have faced “worrying levels of abuse" in past month. BMA Reports. BMJ, 374, n1977. https://doi. org/10.1136/bmj.n1977

Mather, R. D. (2007). Toward a unified social psychology: The integrative social paradigm. Journal of Scientific Psychology, $8-13$.

Mathieu, E., Ritchie, H., Ortiz-Ospina, E., Roser, M., Hasell, J., Appel, C., Giattino, C., \& Rodés-Guirao, L. (2021). A global database of COVID-19 vaccinations. Nature Human Bebaviour, 5(7), 947-953. https://doi.org/10.1038/s4156 2-021-01122-8

Matsick, J. L., Kim, L. M., \& Kruk, M. (2020). Facebook LGBTQ pictivism: The effects of women's rainbow profile filters on sexual prejudice and online belonging. Psychology of Women Quarterly, 44(3), 342-361. https://doi.org/10.1177/0361684320930566

Mazey, S., \& Richardson, J. (2020). Lesson-drawing from New Zealand and Covid-19: The need for anticipatory policy making. The Political Quarterly, 91(3), 561-570. https://doi.org/10.1111/1467-923X.12893

Mokdad, I. (2021). The Lived Experience of Nurses Wearing Facemasks During COVID-19 Pandemic: An Ergonomic Study. Paper presented at the Proceedings of the 21st Congress of the International Ergonomics Association (IEA 2021): Volume IV: Healthcare and Healthy Work.

Nassauer, A. (2019). Situational breakdowns: Understanding protest violence and other surprising outcomes. Oxford University Press.

Neville, F. G., Templeton, A., Smith, J. R., \& Louis, W. R. (2021). Social norms, social identities and the COVID-19 pandemic: Theory and recommendations. Social and Personality Psychology Compass, 15(5), e12596. https://doi.org/10.1111/spc3.12596

Newson, M. (2017). Football, fan violence, and identity fusion. International Review for the Sociology of Sport, 54(4), 431-444. https:// doi.org/10.1177/1012690217731293

Olivera-La Rosa, A., Chuquichambi, E. G., \& Ingram, G. P. D. (2020). Keep your (social) distance: Pathogen concerns and social perception in the time of COVID-19. Personality and Individual Differences, 166, 110200. https://doi.org/10.1016/j.paid.2020.110200

Pagliaro, S., Sacchi, S., Pacilli, M. G., Brambilla, M., Lionetti, F., Bettache, K., Bianchi, M., Biella, M., Bonnot, V., Boza, M., Butera, F., Ceylan-Batur, S., Chong, K., Chopova, T., Crimston, C. R., Álvarez, B., Cuadrado, I., Ellemers, N., Formanowicz, M., ... Zubieta, E. (2021). Trust predicts COVID-19 prescribed and discretionary behavioral intentions in 23 countries. PLoS One, 16(3), e0248334. https://doi.org/10.1371/journal.pone.0248334

Parada-Fernández, P., Herrero-Fernández, D., Jorge, R., \& Comesaña, P. (2022). Wearing mask hinders emotion recognition, but enhances perception of attractiveness. Personality and Individual Differences, 184, 111195. https://doi.org/10.1016/j.paid.2021.111195

Perach, R. (2020). Can culture beat the coronavirus?. School of Psychology Blog, University of Sussex. Retrieved from https://blogs.sussex. ac.uk/psychology/2020/03/19/can-culture-beat-the-coronavirus/

Perach, R., \& Wisman, A. (2019). Can creativity beat death? A review and evidence on the existential anxiety buffering functions of creative achievement. The Journal of Creative Behavior, 53(2), 193-210. https://doi.org/10.1002/jocb.171

Postmes, T., Haslam, S. A., \& Jans, L. (2013). A single-item measure of social identification: Reliability, validity, and utility. British Journal of Social Psychology, 52(4), 597-617. https://doi.org/10.1111/bjso.12006

Prosser, A. M. B., Judge, M., Bolderdijk, J. W., Blackwood, L., \& Kurz, T. (2020). 'Distancers' and 'non-distancers'? The potential social psychological impact of moralizing COVID-19 mitigating practices on sustained behaviour change. British Journal of Social Psychology, 59(3), 653-662. https://doi.org/10.1111/bjso.12399

Pyszczynski, T., Greenberg, J., \& Solomon, S. (1999). A dual-process model of defense against conscious and unconscious death-related thoughts: An extension of terror management theory. Psychological Review, 106(4), 835-845. https://doi. org/10.1037/0033-295X.106.4.835

Pyszczynski, T., Lockett, M., Greenberg, J., \& Solomon, S. (2020). Terror management theory and the COVID-19 pandemic. Journal of Humanistic Psychology, 61(2), 173-189. https://doi.org/10.1177/0022167820959488

Pyszczynski, T., Solomon, S., \& Greenberg, J. (2015). Thirty years of terror management theory: From genesis to revelation. Advances in Experimental Social Psychology, 52, 1-70. https://doi.org/10.1016/bs.aesp.2015.03.001

Rank, O. (1941). Beyond psychology. Dover.

Reicher, S., Spears, R., \& Haslam, S. A. (2010). The social identity approach in social psychology. In M. Wetherell, \& C. T. Mohanty (Eds.), The SAGE handbook of identities (pp. 45-62). SAGE.

Rosa, A.-O.-L., Chuquichambi, E. G., \& Ingram, G. P. D. (2020). Keep your (social) distance: Pathogen concerns and social perception in the time of COVID-19. Personality and Individual Differences, 166, 110200. https://doi.org/10.1016/j.paid.2020.110200

Rosenberg, S., Nelson, C., \& Vivekananthan, P. (1968). A multidimensional approach to the structure of personality impressions. Journal of Personality and Social Psychology, 9(4), 283-294. https://doi.org/10.1037/h0026086

Rosenblatt, A., Greenberg, J., Solomon, S., Pyszczynski, T., \& Lyon, D. (1989). Evidence for terror management theory: I. The effects of mortality salience on reactions to those who violate or uphold cultural values. Journal of Personality and Social Psychology, 57(4), 681-690. 
Scheier, M. F., Carver, C. S., \& Bridges, M. W. (1994). Distinguishing optimism from neuroticism (and trait anxiety, self-mastery, and self-esteem): A reevaluation of the Life Orientation Test. Journal of Personality and Social Psychology, 67(6), $1063-1078$. https://doi.org/10.1037/0022-3514.67.6.1063

Schimel, J., Wohl, M. J. A., \& Williams, T. (2006). Terror management and trait empathy: Evidence that mortality salience promotes reactions of forgiveness among people with high (vs. low) trait empathy. Motivation and Emotion, 30(3), $214-224$. https://doi.org/10.1007/s11031-006-9040-y

Scottish Government [@scotgov] (2020). Staying at home now is an expression of love, kindness and solidarity. We are doing it for each other, not just ourselves [Tweet]. Twitter. https://twitter.com/scotgov/status/1259935387730038784

Simpson, J. A. (2007). Foundations of interpersonal trust. In A. W. Kruglanski, \& E. T. Higgins (Eds.), Socialpsychology: Handbook of basic principles (2nd ed., pp. 587-607). The Guilford Press.

Social Metrics Commission (2020). Measuring poverty 2020. Retrieved from https://socialmetricscommission.org.uk/wp-content/ uploads/2020/06/Measuring-Poverty-2020-Web.pdf

Solomon, S., Greenberg, J., \& Pyszczynski, T. (2004). The cultural animal: Twenty years of terror management theory and research. In J. Greenberg, S. L. Koole, \& T. Pyszczynski (Eds.), Handbook of experimental existential psychology (pp. 13-34). The Guilford Press.

Stubley, P. (2020). Coronavirus: Boris Johnson praises NHS as country's greatest national asset after saying 'he could have gone either way'. The Independent. Retrieved from https:/www.independent.co.uk/news/uk/politics/coronavirus-boris-johnson-healthnews-hospital-nhs-video-tweet-a9461616.html

Tajfel, H. E. (1978). Differentiation between social groups: Studies in the social psychology of intergroup relations. Academic Press.

Tajfel, H., \& Turner, J. C. (1979). An integrative theory of intergroup conflict. In W. G. Austin, \& S. Worchel (Eds.), The social psychology of intergroup relations (pp. 33-47). Brooks/Cole.

Tateo, L. (2020). Face masks as layers of meaning in times of COVID-19. Culture \& Psychology, 27(1), 131-151. https://doi. org $/ 10.1177 / 1354067$ X20957549

Timpka, T., \& Nyce, J. M. (2021). Face mask use during the COVID-19 pandemic - the significance of culture and the symbolic meaning of behavior. Annals of Epidemiology, 59, 1-4. https://doi.org/10.1016/j.annepidem.2021.03.012

Todorov, A., Pakrashi, M., \& Oosterhof, N. N. (2009). Evaluating faces on trustworthiness after minimal time exposure. Social Cognition, 27(6), 813-833. https://doi.org/10.1521/soco.2009.27.6.813

Tomasini, F. (2021). Solidarity in the Time of COVID-19? Cambridge Quarterly of Healthcare Ethics, 30(2), 234-247. https://doi. org/10.1017/S0963180120000791

Turner, J. C., Hogg, M. A., Oakes, P. J., Reicher, S. D., \& Wetherell, M. S. (1987). Rediscovering the social group: A self-categorization theory. Basil Blackwell.

Turner, J. C., Oakes, P. J., Haslam, S. A., \& McGarty, C. (1994). Self and collective: Cognition and social context. Personality and Social Psychology Bulletin, 20(5), 454-463. https://doi.org/10.1177/0146167294205002

Tybur, J. M., Lieberman, D., \& Griskevicius, V. (2009). Microbes, mating, and morality: Individual differences in three functional domains of disgust. Journal of Personality and Social Psychology, 97-122(1), 103. https://doi.org/10.1037/a0015474

UK Government (2021a). Coronavirus (Covid-19) in the UK: Cases in the United Kingdom. Retrieved from https://coronavirus.data. gov.uk/details/cases

UK Government (2021b). Further easing of COVID restrictions confirmed for 17 May. Retrieved from https://www.gov.uk/gover nment/news/further-easing-of-covid-restrictions-confirmed-for-17-may

Vail, K. E., Juhl, J., Arndt, J., Vess, M., Routledge, C., \& Rutjens, B. T. (2012). When death is good for life: Considering the positive trajectories of terror management. Personality and Social Psychology Review, 16(4), 303-329. https://doi.org/10.1177/10888 68312440046

van Bavel, J. J., \& Packer, D. J. (2021). The power of us: Harnessing our shared identities to improve performance, increase Cooperation, and promote social harmony. Little, Brown and Co.

van Dick, R., Stellmacher, J., Wagner, U., Lemmer, G., \& Tissington, P. A. (2009). Group membership salience and task performance. Journal of Managerial Psychology, 24(7), 609-626. https://doi.org/10.1108/02683940910989011

Van Gorp, B. (2021). Face masks as floating signifiers during the COVID-19 pandemic in Belgium. Visual Studies, 36(2), 124132. https://doi.org/10.1080/1472586X.2021.1915703

Watson, D., Clark, L. A., \& Tellegen, A. (1988). Development and validation of brief measures of positive and negative affect: The PANAS scales. Journal of Personality and Social Psychology, 54, 1063-1070. https://doi.org/10.1037/002 2-3514.54.6.1063

Wei, J., Guo, S., Long, E., Zhang, L., Shu, B., \& Guo, L. (2021). Why does the spread of COVID-19 vary greatly in different countries? Revealing the efficacy of face masks in epidemic prevention. Epidemiology and Infection, 149, e24. https://doi. org/10.1017/S0950268821000108

Wirth-Petrik, B., \& Guenther, R. K. (2012). Mortality salience and symbols of cultural worldview affect the desirability of a stressful job: The ironic consequences of terror management. Psychological Reports, 111(3), 717-723. https://doi. org/10.2466/07.15.PR0.111.6.717-723

Wolowic, J. M., Heston, L. V., Saewyc, E. M., Porta, C., \& Eisenberg, M. E. (2017). Chasing the rainbow: lesbian, gay, bisexual, transgender and queer youth and pride semiotics. Culture, Health \& Sexuality, 19(5), 557-571. https://doi.org/10.1080/13691 058.2016.1251613 
World Health Organization (2020). WHO Director-General's opening remarks at the media briefing on COVID-19 - 11 March 2020. Retrieved from https://www.who.int/director-general/speeches/detail/who-director-general-s-opening-remarks-at-themedia-briefing-on-covid-19--11-march-2020

World Health Organization (2021). Coronavirus disease (COVID-19) advice for the public: When and how to use masks. Retrieved from https://www.who.int/emergencies/diseases/novel-coronavirus-2019/advice-for-public/when-and-how-to-use-masks

Wu, G., Liang, L., \& Gursoy, D. (2021). Effects of the new COVID-19 normal on customer satisfaction: Can facemasks level off the playing field between average-looking and attractive-looking employees? International Journal of Hospitality Management, 97, 102996. https://doi.org/10.1016/j.ijhm.2021.102996

Wu, T., Jia, X., Shi, H., Niu, J., Yin, X., Xie, J., \& Wang, X. (2021). Prevalence of mental health problems during the COVID-19 pandemic: A systematic review and meta-analysis. Journal of Affective Disorders, 281, 91-98. https://doi.org/10.1016/j. jad.2020.11.117

Yan, Y., Nie, J., Huang, L., Li, Z., Cao, Q., \& Wei, Z. (2015). Is your first impression reliable? Trustworthy analysis using facial traits in portraits. In X. He, S. Luo, D. Tao, C. Xu, J. Yang, \& M. A. Hasan (Eds), MultiMedia modeling. MMM 2015. Lecture notes in computer science (Vol. 8936). Springer, Cham. https://doi.org/10.1007/978-3-319-14442-9_13

How to cite this article: Perach, R., \& Limbu, M. (2022). Can culture beat Covid-19? Evidence that exposure to facemasks with cultural symbols increases solidarity. British Journal of Social Psychology, 00, 1-20. https://doi.org/10.1111/bjso.12521 